\title{
Substratos alternativos ao esfagno na aclimatização de plântulas de Arundina graminifolia "alba" (Orchidaceae) ${ }^{(1)}$
}

\author{
ANA PAULA ZANDONÁ(2), RICARDO TADEU DE FARIA(3), \\ ALESSANDRO BORINI LONE ${ }^{(4)}$ e RODRIGO THIBES HOSHINO(5)
}

\begin{abstract}
RESUMO
A Arundina graminifolia, é conhecida popularmente como orquídea bambu, por apresentar seus caules bastante extensos. É muito utilizada no ramo paisagístico, sendo uma planta bastante rústica. O esfagno é o substrato mais usado na aclimatização de orquídeas, entretanto questões ambientais têm gerado um aumento na pesquisa por substratos alternativos. O objetivo deste trabalho foi avaliar substratos alternativos ao uso do esfagno na aclimatização de $A$. graminifolia. Os substratos utilizados foram: esfagno; casca de arroz carbonizada; casca de arroz carbonizada + fibra de coco 1:1 (v/v); esfagno + casca de arroz carbonizada 1:1 (v/v). As plântulas foram mantidas em casa de vegetação e depois de sete meses foram avaliadas a taxa de sobrevivência $(\%)$, altura da parte aérea $(\mathrm{cm})$, comprimento médio de raiz $(\mathrm{cm})$, número de folhas e raízes, massa seca de folhas, pseudobulbos e raízes $(\mathrm{g})$ e a área foliar $\left(\mathrm{mm}^{2}\right)$. Ainda foram avaliados o $\mathrm{pH}$, condutividade $\left(\right.$ uS.cm $\left.{ }^{-1}\right)$, densidade $\left(\right.$ g. $\left.\mathrm{cm}^{-3}\right)$ e capacidade de retenção de água $\left(\mathrm{mL} . \mathrm{L}^{-1}\right)$ dos substratos. Os resultados mostraram valores elevados de sobrevivência $(80 \%)$ e de número de folhas $(4,3)$ nas plantas cultivadas em casca de arroz carbonizada + fibra de coco $(1: 1 \mathrm{v} / \mathrm{v})$. O mesmo apresentou $\mathrm{pH}(5,9)$ dentro da faixa ideal de disponibilidade de nutriente. Conclui-se que a mistura de casca de arroz carbonizada + fibra de $\operatorname{coco}(1: 1 \mathrm{v} / \mathrm{v})$ é um substrato adequado para o desenvolvimento vegetativo de A. graminifolia durante a fase de aclimatização, podendo substituir o esfagno, sendo o uso do substrato casca de arroz carbonizada isoladamente inviável durante esta etapa.

Palavras-chave: orquídea bambu; desenvolvimento vegetativo; orquídea.
\end{abstract}

\begin{abstract}
Alternative substrates to the sphagnum moss in the acclimatization of arundina graminifolia "alba"(Orchidaceae) The Arundina graminifolia, is popularly known as bamboo orchid, by having their stems quite extensive. It is widely used in the business landscape, with a very rustic plant. Sphagnum moss is the most widely used substrate in the acclimatization of orchids, but environmental issues have led to an increase in the search for alternative substrates. The objective of this study was to evaluate substrates that can replace all or part of the use of sphagnum moss on the acclimatization of $A$. graminifolia. The substrates used were: sphagnum moss, rice hulls, rice hulls + coir 1:1 (v/v) sphagnum + carbonized rice husk, 1:1 (v/ v). Seedlings were kept in a greenhouse and after seven months were evaluated for survival rate (\%), shoot height $(\mathrm{cm})$, average root length $(\mathrm{cm})$, number of leaves and roots, dry leaves, pseudobulbs and roots $(\mathrm{g})$ and leaf area $\left(\mathrm{mm}^{2}\right)$. Also evaluated were $\mathrm{pH}$, conductivity $\left(\mathrm{uS} . \mathrm{cm}^{-1}\right)$, density $\left(\mathrm{g} . \mathrm{cm}^{-3}\right)$ and water holding capacity $\left(\mathrm{mL} . \mathrm{L}^{-1}\right)$ were evaluated. The results showed high levels of survival (80\%) and the number of leaves (4.3) grown plants in rice hulls + coconut fiber 1:1 (v/v). The same with respect to $\mathrm{pH}(5.9)$ within the optimal range of nutrient availability. It is concluded that the mixture of rice hulls + coconut fiber $1: 1(\mathrm{v} / \mathrm{v})$, is a suitable substrate for plant growth $A$. graminifolia during the acclimatization phase, which may replace the sphagnum, and the use of carbonized rice husk alone unfeasible during this period. Keywords: bamboo orchid; vegetative growth; orchid.
\end{abstract}

\section{INTRODUÇÃO}

A espécie Arundina graminifolia é popularmente conhecida como orquídea bambu, por apresentar seus caules bastante extensos, floresce da primavera ao início de outono, exibe uma inflorescência lilás rosada com o labelo púrpura, ocorrendo também na coloração branca e é muito utilizada nos jardins contemporâneos (PATRO, 2012).

As orquídeas têm um desenvolvimento vegetativo lento, visto que uma divisão de muda leva, no mínimo, dois anos, e dos milhões de sementes produzidas em cápsula, somente $5 \%$ germinam na natureza. O cultivo através de sementes em meio de cultura permite acelerar esse processo e elevar a taxa de germinação, tornando o processo de multiplicação comercialmente viável (STANCATO e FARIA, 1996; STANCATO et al., 2001).

Após o crescimento in vitro, há necessidade de retirar as plantas dos frascos para que as mesmas se adaptem às condições do ambiente, onde podem ocorrer mudanças de natureza morfológica, anatômica e fisiológica (SUTTER et al., 1992). Nessa fase, a planta passa de uma condição heterotrófica onde o meio de cultura oferece todo suprimento externo necessário, para uma condição autotrófica, precisando realizar a fotossíntese de forma mais eficiente para sobreviver (GEORGE, 1993). Essa fase de aclimatização é delicada, não só porque representa um estresse para a plântula, mas também pelo período de infecção por fungos e bactérias que podem se desenvolver neste estágio (TOM-

\footnotetext{
${ }^{(1)}$ Trabalho recebido para publicação em 21/05/2012 e aprovado em 04/02/2014

(2) Bolsista, IC Fundação Araucária

(3) Professor do Departamento de Agronomia, UEL, Rod. Celso Garcia Cid, Cx. Postal 6001, 86051-990, Londrina, Paraná, Brasil, e-mail: faria@uel.br

(4) Doutorando em Agronomia, UEL

(5) Mestrando em Agronomia, UEL, email: rodrigohoshino@gmail.com
} 
BOLATO e COSTA, 1998). Segundo Moraes at al. (2002), é necessário nesta etapa que a plântula esteja em um substrato que lhe propicie boas condições para seu melhor desenvolvimento.

Dentre os substratos mais utilizados por viveiristas e orquidófilos na aclimatização de plântulas está o esfagno. O esfagno é um musgo que cresce em regiões denominadas turfas, sendo que esta cobre somente $3 \%$ da superfície terrestre (CHARMAN, 2002). Estudos atribuem a estas regiões como sendo um reservatório de carbono terrestre, com potencial a mudanças climáticas globais, sendo vital a preservação destes ecossistemas (FROLKING et al., 2006). Estudos recentes têm se dedicado à preservação e ao manejo destes ecossistemas (FUKUTA et al., 2011; BULLOCK, 2012).

A preocupação com a pesquisa de substratos alternativos ao esfagno já vem sendo tratada há algum tempo por Evans e Stamps (1996), estudos que relataram questões como aumentos de pressões e preocupações ambientais. No Brasil, a coleta do esfagno à beira dos rios é proibida pelo Ibama, (SOUZA, 2003) sendo o esfagno utilizado importado de turfas chilenas.

Existem inúmeros substratos que podem ser utilizados para aclimatização de orquídeas, como: a casca de pínus, fibra de coco, pó de coco, fibra de piaçava, casca de arroz carbonizada, vermiculita, carvão, isopor entre outros. (MORAES, 2002; COLOMBO, 2005; ARAUJO, 2007; STEFANELLO, 2009).

O substrato utilizado deve apresentar características satisfatórias quanto à economia hídrica, aeração, permeabilidade, poder de tamponamento para valores de $\mathrm{pH}$ e capacidade para retenção de nutrientes (FARIA et al., 2010).

$\mathrm{O}$ objetivo deste trabalho foi avaliar substratos alternativos ao uso do esfagno na aclimatização de $A$. graminifolia.

\section{MATERIAL E MÉTODOS}

O experimento foi conduzido durante os meses de novembro de 2009 a Julho de 2010, no Centro de Ciências Agrárias da Universidade Estadual de Londrina, Estado do Paraná (Latitude 23⒉' Longitude 51 ${ }^{\circ} 11^{\prime}$; altitude média $566 \mathrm{~m}$ ). O clima da região é Cfa (subtropical úmido), segundo a classificação de W. Köppen.

As plântulas foram obtidas de semeadura in vitro da or- quídea $A$. graminifolia. Após nove meses, as plântulas foram retiradas dos frascos e lavadas com água corrente para a eliminação do meio de cultura.

Os substratos avaliados foram: esfagno; casca de arroz carbonizada; casca de arroz carbonizada + fibra de coco $(1: 1 \mathrm{v} / \mathrm{v})$; esfagno + casca de arroz carbonizada $(1: 1 \mathrm{v} / \mathrm{v})$.

A casa de vegetação utilizada durante o período de aclimatização apresentava sua estrutura em cumeeira, coberta com telhas transparente e suas laterais recobertas com tela de polipropileno, com retenção de $40 \%$ do fluxo de radiação solar.

Foram utilizadas bandejas de isopor com $21,5 \mathrm{~cm}$ de comprimento, $14,5 \mathrm{~cm}$ de largura, $4,5 \mathrm{~cm}$ de altura, apresentando seis furos na parte inferior para garantir uma melhor drenagem e aeração do sistema radicular. As plantas foram mantidas na casa de vegetação em mesas suspensas, recebendo adubação mensal do adubo Biofert Plus ${ }^{\circledR}$ de formulação N-P-K(8-9-9), na concentração $3 \mathrm{~mL} . \mathrm{L}^{-1}$, sendo aplicado 50 $\mathrm{mL}$ por vaso. As plantas foram irrigadas diariamente durante o verão e três vezes por semana no inverno, recebendo cerca de $250 \mathrm{~mL} /$ rega. As regas foram realizadas manualmente até saturação do substrato.

Após sete meses de plantio, foram feitas as seguintes avaliações: taxa de sobrevivência das plântulas (\%), altura da parte aérea $(\mathrm{cm})$, comprimento médio de raiz $(\mathrm{cm})$, número de folhas e raízes, massa seca de folhas, pseudobulbos e raiz (g), o software ImageJ foi utilizado para medir a área foliar $\left(\mathrm{mm}^{2}\right)$ (RASBAND 2006). Dos substratos, foram avaliados o $\mathrm{pH}$, condutividade $\left(\mathrm{uS} . \mathrm{cm}^{-1}\right)$, densidade $\left(\mathrm{g} . \mathrm{cm}^{-3}\right)$ e capacidade de retenção de água $\left(\mathrm{mL} \cdot \mathrm{L}^{-1}\right)$.

O delineamento do experimento foi inteiramente casualizado com cinco repetições e 20 plântulas por parcela. Os dados foram submetidos a análise de variância e as médias comparadas pelo teste de Tukey, em nível de $5 \%$ de probabilidade.

\section{RESULTADO E DISCUSSÃO}

Nos resultados referentes à porcentagem de sobrevivência das plântulas pode-se verificar que os substratos que combinavam em proporções iguais a fibra de coco + casca de arroz e esfagno + casca de arroz não diferiram estatisticamente do esfagno, o qual somente diferiu da casca de arroz carbonizada quando utilizada isoladamente (Tabela 1).

Tabela1. Porcentagem de sobrevivência (PS), altura da parte aérea (APA), comprimento médio de raízes (CMR), média do número de folhas (NF) e número de raízes (NR).

Table 1. Percentage of survival (PS), shoot height (APA), average length of roots (CMR), average number of leaves (NF) and number of roots (NR).

\begin{tabular}{|c|c|c|c|c|c|}
\hline Substratos & PS (\%) & APA $(\mathbf{c m})$ & $\mathbf{C M R}(\mathbf{c m})$ & $\mathbf{N F}$ & $\mathbf{N R}$ \\
\hline $\mathrm{E}^{1}$ & $83 \mathrm{a}^{2}$ & $7,35 \mathrm{a}$ & $4,79 \mathrm{a}$ & $3,8 \mathrm{ab}$ & $3,9 \mathrm{a}$ \\
\hline $\mathrm{CAC}$ & $50 \mathrm{~b}$ & $5,57 \mathrm{a}$ & $4,16 \mathrm{a}$ & $3,2 \mathrm{~b}$ & $4,1 \mathrm{a}$ \\
\hline $\mathrm{CAC}+\mathrm{FC}$ & $80 \mathrm{ab}$ & $6,39 \mathrm{a}$ & $3,94 \mathrm{a}$ & $4,3 \mathrm{a}$ & $5,5 \mathrm{a}$ \\
\hline $\mathrm{E}+\mathrm{CAC}$ & $65 \mathrm{ab}$ & $4,88 \mathrm{a}$ & $5,17 \mathrm{a}$ & $3,7 \mathrm{ab}$ & $3,5 \mathrm{a}$ \\
\hline $\mathrm{CV}(\%)$ & 25 & 37,25 & 24,59 & 14,6 & 25,9 \\
\hline
\end{tabular}

${ }^{1} \mathrm{E}$ : esfagno; CAC: casca de arroz carbonizada; CAC + FC: casca de arroz carbonizada + fibra de coco $(1: 1 \mathrm{v} / \mathrm{v})$; E + CAC: esfagno + casca de arroz carbonizada $(1: 1 \mathrm{v} / \mathrm{v}) ;{ }^{2}$ médias seguidas da mesma letra na coluna não diferem entre si pelo teste Tukey a $5 \%$ de probabilidade. 
A porcentagem de sobrevivência é uma característica determinante na escolha do substrato onde é possível verificar que para as demais características o desenvolvimento foi pouco afetado. É possível observar que, para as variáveis área foliar e massa seca de folha, pseudobulbo e parte aérea, não ocorreram diferenças significativas entre os tratamentos. Esses resultados mostram que os diferentes substratos utilizados praticamente não influenciaram o ganho de massa nas diferentes partes da planta e nem no aumento da área fotossintética (Tabela 2).

Tabela 2. Valores médios de área foliar (AF), massa seca de folhas (MSF), massa seca de pseudobulbo (MSP) e massa seca da parte aérea (MSPA).

Table 2. Mean values of leaf area (AF), leaf dry mass (MSF), dry weight of pseudobulb (MSP) and dry mass (MSPA).

\begin{tabular}{|c|c|c|c|c|}
\hline Substratos & AF (mm $\mathbf{m m}^{\mathbf{2}}$ & MSF (g) & MSP (g) & MSPA (g) \\
\hline $\mathrm{E}^{1}$ & $1025,20 \mathrm{a}^{2}$ & $0,05 \mathrm{a}$ & $0,05 \mathrm{a}$ & $0,09 \mathrm{a}$ \\
\hline CAC & $771,28 \mathrm{a}$ & $0,03 \mathrm{a}$ & $0,06 \mathrm{a}$ & $0,09 \mathrm{a}$ \\
\hline CAC + FC & $1128,76 \mathrm{a}$ & $0,05 \mathrm{a}$ & $0,04 \mathrm{a}$ & $0,08 \mathrm{a}$ \\
\hline E + CAC & $1004,48 \mathrm{a}$ & $0,04 \mathrm{a}$ & $0,04 \mathrm{a}$ & 33,63 \\
\hline CV $(\%)$
\end{tabular}

${ }^{1}$ E: esfagno; CAC: casca de arroz carbonizada; CAC + FC: casca de arroz carbonizada + fibra de coco $(1: 1 \mathrm{v} / \mathrm{v})$; E + CAC: esfagno + casca de arroz carbonizada $(1: 1 \mathrm{v} / \mathrm{v}) ;{ }^{2}$ médias seguidas da mesma letra na coluna não diferem entre si pelo teste Tukey a $5 \%$ de probabilidade.

Colombo et al. (2005), em seu trabalho de aclimatização com substratos vegetais sob dois sistemas de irrigação para a orquídea Cattleya, verificou que o esfagno foi o que proporcionou a menor taxa de sobrevivência para as plantas. Isso mostra que existe variação em relação a sobrevivência entre os gêneros de orquídeas, mostrando que um substrato que é adequado para uma determinada orquídea pode ser inadequado para outra. Entretanto, quando o mesmo autor avaliou o desenvolvimento das plantas pela altura da parte aérea e número de raízes, o mesmo não encontrou diferenças estatísticas entre os substratos.

Em relação ao número de folhas, o cultivo em casca de arroz carbonizada mostrou-se pouco eficiente em relação à fibra de coco + casca de arroz carbonizada (Tabela 1). Pesquisas com uso da fibra de coco pura ou em mistura no cultivo de diferentes espécies de plantas ornamentais têm demonstrado o desempenho superior desta em relação a outros substratos (MEEROW, 1994; 1995; MAK e YEH, 2001).

Lone et al. (2008), estudando diferentes substratos na aclimatização de Cattleya (Orchidaceae), verificaram que a casca de arroz carbonizada teve desempenho inferior à fibra de coco, para a variável comprimento da parte área, tendo também o pior desempenho em número de pseudobulbos, mostrando que o uso da casca de arroz como substrato único afeta o desenvolvimento das plântulas.

O baixo desempenho da casca de arroz pode ser explicado devido ao mesmo ter apresentado alta densidade, sendo estatisticamente superior aos demais e pela sua também alta capacidade de retenção de água, prejudicado a aeração do substrato (Tabela 3). Segundo Kämpf (2000), substratos muito densos podem prejudicar a aeração e o crescimento das raízes.

Com relação à capacidade de retenção de água (Tabela
3), os substratos casca de arroz e casca de arroz + fibra de coco, apresentaram resultados superiores em relação ao esfagno, entretanto o esfagno apresentou bons resultados em relação à sobrevivência e desenvolvimento vegetativo, mostrando que essa orquídea pode se desenvolver bem em substrato com baixa umidade.

O tratamento contendo casca de arroz carbonizada + fibra de coco apresentou a maior condutividade elétrica (1413,0 uS.cm ${ }^{-1}$ ) (Tabela 3). De acordo com Booman (1999), a fibra de coco apresenta desvantagens de possuir uma condutividade elétrica muito alta que limita o crescimento das raízes. Segundo Takane et al. (2006), valor de salinidade superior a $500,00 \mu \mathrm{S}$ é elevado para orquídeas epífitas, podendo causar perda de água pelas raízes. Entretanto, como a Arundina graminifolia é uma orquídea terrestre apesar dos elevados resultados de condutividade elétrica no tratamento contendo fibra de coco, não houve diferença significativa no crescimento das raízes (Tabela. 1).

Em relação à densidade, o substrato esfagno mostrou-se menos denso em relação aos demais, o que é apontado como vantajoso em relação à maior facilidade no manuseio dos vasos e a não necessidade de bancadas com estrutura reforçada o que poderia aumentar os custos na implantação de uma casa de vegetação. Contudo, apesar da casca de arroz carbonizada e a mistura fibra de coco + casca de arroz mostrarem valores estatisticamente superiores ao esfagno, eles ainda são considerados substratos de baixa densidade, por apresentarem uma porosidade elevada.

Segundo Sanches (1999), a fibra de coco apresenta porosidade total de $95,6 \%$, retenção de água de $538 \mathrm{~mL} \mathrm{~L}^{-1}$, capacidade de aeração de $45,5 \%$ e água facilmente assimilável de 19,8\%, que, segundo Noguera et al. (2000), são valores que conferem ao substrato características de boa qualidade. 
Tabela 3. Valores médios de potencial hidrogeniônico $(\mathrm{pH})$, condutividade elétrica $(\mathrm{CE})$, capacidade de retenção de água (CR) e densidade (D) dos substratos.

Table 3. Mean values of hydrogen potential $(\mathrm{pH})$, electrical conductivity $(\mathrm{CE})$, water retention capacity (CR) and density (D) of the substrates.

\begin{tabular}{|c|c|c|c|c|}
\hline Substratos & $\mathbf{p H}$ & $\mathbf{C E}\left(\boldsymbol{\mu S} \cdot \mathbf{c m}^{-\mathbf{1}}\right)$ & $\mathbf{C R}\left(\mathbf{m L} \cdot \mathbf{L}^{-\mathbf{1}}\right)$ & $\mathbf{D}\left(\mathbf{g . c m} \mathbf{c m}^{-\mathbf{3}}\right)$ \\
\hline $\mathrm{E}^{1}$ & $5,7 \mathrm{a}^{2}$ & $52,3 \mathrm{~d}$ & $518,06 \mathrm{~b}$ & $0,02 \mathrm{~d}$ \\
\hline CAC & $6,0 \mathrm{a}$ & $473,8 \mathrm{~b}$ & $813,89 \mathrm{a}$ & $0,16 \mathrm{a}$ \\
\hline CAC + FC & $5,9 \mathrm{a}$ & $1413,0 \mathrm{a}$ & $724,07 \mathrm{a}$ & $0,14 \mathrm{~b}$ \\
\hline $\mathrm{E}+\mathrm{CAC}$ & $6,0 \mathrm{a}$ & $169,8 \mathrm{c}$ & $656,94 \mathrm{ab}$ & $0,06 \mathrm{c}$ \\
\hline CV $(\%)$ & 4,4 & 8,7 & 14,34 & 4,29 \\
\hline
\end{tabular}

${ }^{1} \mathrm{E}$ : esfagno; CAC: casca de arroz carbonizada; CAC + FC: casca de arroz carbonizada + fibra de coco (1:1 v/v); E + CAC: esfagno + casca de arroz carbonizada $(1: 1 \mathrm{v} / \mathrm{v}) ;{ }^{2}$ médias seguidas da mesma letra na coluna não diferem entre si pelo teste Tukey a $5 \%$ de probabilidade.

\section{CONCLUSÃo}

A mistura de casca de arroz carbonizada + fibra de coco (1: $1 \mathrm{v} / \mathrm{v})$, mostrou ser o substrato mais indicado para o desenvolvimento vegetativo de Arundina graminifolia durante a fase de aclimatização, podendo este substituir o uso do esfagno; a casca de arroz carbonizada isoladamente não demonstrou bons resultados na aclimatização.

\section{REFERÊNCIAS}

ARAUJO, A. G.; PASQUAL, M.; DUTRA, L. F.; CARVALHO, J. G.; SOARES, G. A. Substratos alternativos ao xaxim e adubação de plantas de orquídea na fase de aclimatização. Ciência Rural, Santa Maria, v.37, n.2, p. 560-571, 2007.

BOOMAN, J. L. E. Evolução dos substratos usados em horticultura ornamental na Califórnia. In: KAMPF, A. N.; FERMINO, M. H. Substratos para plantas a base da produção vegetal em recipientes. Porto Alegre: Gênesis, 1999. p. 43-65.

BUlloCK, C. H.; COLLIER, M. J.; CONVERY, F. Peatlands, their economic value and priorities for their future management - Theex ample of Ireland. Land Use Policy,.V29, p. 921-928, 2012.

CHARMAN, D. J. Peatlands and Environmental Change. Chichester, UK: John Wiley \& Sons, 2002. 301p.

COLOMBO, L. A.; FARIA, R. T.; ASSIS, A. M.; FONSECA, I. C. B. Aclimatização de um híbrido de Cattleya em substratos de origem vegetal sob dois sistemas de irrigação. Acta Scientiarum Agronomy, Maringá, v. 27, n. 1, p. 145-150, 2005.

EVANS, M. R.; STAMPS, R. H. Growth of Bedding Plants in Sphagnum Peat and Coir Dust-Based Substrates. Journal of Environmental Horticulture, Flórida, v. 14, n. 4, p. 187-190, 1996.
FARIA, R. T.; ASSIS, A. M.; CARVALHO, J. F. R. P. Cultivo de orquídeas. Londrina: Mecenas, 2010. 208p.

FROLKING, S.; ROULET, N. T.; FUGLESTVEDT, J. How northern peatlands influence the Earth's radiative budget: sustained methane emission versus sustained carbon sequestration. Journal of Geophysical Research, s.n.t., 2006.

FUKUTA, E.; SASAKI, A.; NAKATSUBO, T. Microclimate and production of peat moss Sphagnum palustre L. in the warm-temperate zone. Plant Species Biology, v. 27, p. 110-118, 2012.

GEORGE, E. F. Plant propagation by tissue culture: the technology. 2. ed. England: Exegetics, 1993. 508p.

KAMPF, A. N. Produção Comercial de Plantas Ornamentais. Guaíba: Agropecuária, 2000. 254p.

LONE, A. B.; BARBOSA, C. M.; TAKAHASHI, L. S. A.; FARIA, R. T. Aclimatização de Cattleya (Orchidaceae), em substratos alternativos ao xaxim e ao esfagno. Acta Scientiarum Agronomy, Maringá, v. 30, n. 4, p. 465-469, 2008.

MAK, A. T. Y.; YEH, D. M. Nitrogen nutrition of Spathiphyllum 'Sensation' grown in Sphagnum peat-and coir-based media with two irrigation methods. Horticultural Science, Alexandria, v. 36, n. 4, p. 645-649, 2001.

MEEROW, A. W. Growth of two subtropical ornamentals using coir (coconut mesocarp pith) as a peat substitute. Horticultural Science, Alexandria, v. 29, n. 12, p. 14841486, 1994.

MEEROW A. W. Growth of two tropical foliage plants using coir dust as a container medium amendment. Hort Technology, Alexandria, v. 5, n. 3, p. 237-239, 1995. 
MORAES, L. M.; CAVALCANTE, L. C. D.; FARIA, R. T.Substratos para aclimatização de plântulas de Dendrobium nobile Lindl. (Orchidaceae) propagadas in vitro. Acta Scientiarum Agronomy, Maringá, v. 24, n. 5, p. 13971400, 2002.

NOGUERA, P. A. M.; NOGUERA, V.; PUCHADES, R.; MAQUIEIRA, A. Coconut coir waste, a new and viable ecologically friendly peat substitute. Acta Horticulturae, Brussels, v. 517, n. 1, p. 279-286, 2000.

PATRO, R. Orquidea bambu - Arundina spp. Disponível em: http://www.jardineiro.net/br/banco/arundina_bambusifolia.php, Acesso em: 28 mar 2012.

RASBAND, W.; FERREIRA, T. ImageJ User Guide. Disponível em: http://rsb.info.nih.gov/ij/docs/user-guide.pdf, Acesso em: 12 jan 2012.

SANCHES, F. P. Propiedades y características de los sustratos: turba y fibra de coco. In: FERNÁNDEZ, M. F.; GÓMEZ, I. M. C. (Ed). Cultivo sin suelo II: curso superior de especializacón. Almería: Dirección Gen. De Investigación y Formación Agraria de la Junta de Andalucía/FIAPA/ Caja Rural de Almería, p. 65-92, 1999.
SOUZA, M. Muito além do xaxim. Natureza, São Paulo, v. 1, n. 2, p. 32-37, 2003.

STANCATO, G. C.; FARIA R. T. In vitro growth and mineral nutrition of the lithophytic orchid Laelia cinnabarina Batem (Orchidaceae) Lindleyana. West Palm Beach, v. 11, n. 1, p. 41-43, 1996.

STANCATO, G. C.; BEMELMANS P. F.; VEGRO C. L. R. Produção de mudas de orquídeas a partir de sementes in vitro e sua viabilidade econômica: estudo de caso. Revista Brasileira de Horticultura Ornamental, Campinas, v. 7, n. 1, p. 25-33, 2001.

SUTTER, E. G.; SHACKEL, K.; DÍAZ, J. C. Acclimatization of tissue cultured plants. Acta Horticulturae, v. 314, p. 115-119, 1992.

TAKANE, R. J.; FARIA, R. T.; ALTAFIN, V. L. Tecnologia fácil - 75: cultivo de orquídeas. Brasília: LK. 2006. $131 \mathrm{p}$.

TOMBOLATO, A. F. C; COSTA, A. M. M. Micropropagação de plantas ornamentais. Campinas: Instituto Agronômico, 1998. (Boletim Técnico, 174). 